TITLE:

\title{
Effects of ambient pressure on Cu Ka X-ray radiation with millijoule and high-repetition- rate femtosecond laser
}

\section{$\operatorname{AUTHOR}(\mathrm{S}):$}

Hada, M.; Matsuo, J.

\section{CITATION:}

Hada, M....[et al]. Effects of ambient pressure on Cu Ka X-ray radiation with millijoule and high-repetition-rate femtosecond laser. Applied Physics B 2010, 99(1-2): 173-179

ISSUE DATE:

2010-04

URL:

http://hdl.handle.net/2433/128857

\section{RIGHT:}

The original publication is available at www.springerlink.com; この論文 は出版社版でありません。引用の際には出版社版をご確認ご利用くだ さい。; This is not the published version. Please cite only the published version. 


\title{
Effects of ambient pressure on $\mathrm{Cu} \mathbf{K} \alpha$
}

\section{$\mathrm{X}$-ray radiation with millijoule and}

\section{high-repetition-rate femtosecond laser}

\author{
M. Hada ${ }^{1}$, J. Matsuo ${ }^{2 \star}$ \\ 1 Department of Nuclear Engineering, Kyoto University \\ 2 Quantum Science and Engineering Center, Kyoto University
}

Received: date / Revised version: date

\begin{abstract}
Laser-plasma-induced hard $\mathrm{Cu} \mathrm{K} \alpha \mathrm{X}$-ray radiation was generated with millijoule and high-repetition-rate $\mathrm{Ti}$ : sapphire laser in various ambient conditions; in air, in helium or in vacuum $\left(2.7 \mathrm{~Pa}-1.3 \times 10^{4} \mathrm{~Pa}\right)$.
\end{abstract}

* M. Hada

Department of Nuclear Engineering, Kyoto University

Gokasho, Uji, Kyoto, 611-0011, Japan

fax: +81-774-38-3978, tel: +81-774-38-3978

e-mail: hadamasaki@nucleng.kyoto-u.ac.jp

J. Matsuo

Quantum Science and Engineering Center, Kyoto University,

Gokasho, Uji, Kyoto, 611-0011,Japan 
The characteristic X-ray was obtained by focusing the $0.06-1.46 \mathrm{~mJ} / \mathrm{pulse}$, $100 \mathrm{fs}, 1 \mathrm{kHz}$ repetition femtosecond laser onto a solid copper target to a spot $4.8 \mu \mathrm{m}$ in diameter. The relationship between $\mathrm{K} \alpha$ X-ray conversion efficiency and atmospheric conditions was explained with a simple electron collision model. This model suggested that the electron mean free path is the important parameter in the generation of ultrafast pulsed X-rays in any ambient condition. We also demonstrated a high-intensity X-ray source in helium at atmospheric pressure.

PACS 52.38.Ph, 52.50.Jm

\section{Introduction}

When a high-intensity laser pulse is focused onto a metal target, the surface of the target turns into a near-solid-density plasma by ionization of the target materials. The absorption process of the laser pulse into the surface materials varies with the intensity of the laser-produced plasma. The plasma intensity, generated on the laser focusing spot, is the key parameter for the absorption process of laser pulse into the materials and generation process of laser-plasma induced X-ray. The plasma intensity is calculated with the laser power of a single pulse, its pulse duration, wavelength and the diameter of focusing spot. In the lower plasma intensity $\left(\mathrm{I} \lambda^{2}\right)$ range, $\mathrm{I} \lambda^{2}<1 \times$ $10^{15} \mathrm{~W} \mu \mathrm{m}^{2} / \mathrm{cm}^{2}$, almost all of the absorbed laser energy transfers through collisional processes, such as inverse-bremsstrahlung [1-3]. In the plasma intensity range of $1 \times 10^{15}-4 \times 10^{16} \mathrm{~W} \mu \mathrm{m}^{2} / \mathrm{cm}^{2}$, laser-produced plasmas 
are reportedly absorbed into the target via a more complicated collisionless process like resonant absorption [3-7]. In the higher plasma intensity range, $\mathrm{I} \lambda^{2}>4 \times 10^{16} \mathrm{~W} \mu \mathrm{m}^{2} / \mathrm{cm}^{2}$, the dominant absorption processes of laserproduced plasma are turned into vacuum heating [8]. Some other processes are important above plasma intensities of $\mathrm{I} \lambda^{2}>1 \times 10^{17} \mathrm{~W} \mu \mathrm{m}^{2} / \mathrm{cm}^{2}$, such as Raman heating or the two-dimensional effect $[9,10]$. Hot electrons are created in the near surface region of the target with energy of 1-5 keV [11]. The hot electrons in the laser plasma interact with the incident laser pulse and are accelerated into the solid target. As the high-energy electrons penetrate into the target material, X-rays are generated via ionization of the target material by the high-energy electrons, or bremsstrahlung. These X-rays are generated when the hot electron is on the target surface, and thus the pulse duration of these laser-produced X-rays is similar to the incident laser pulse, i.e., several hundred fs [12]. The laser-produced X-rays have gained much interest, as unique time-resolved X-ray diffraction (XRD) experiments demonstrate the atomic dynamics of chemical reactions, phase transition and coherent phonon vibrations [12-17]. For these time-resolved XRD experiments, a short-pulsed and high-intensity X-ray source of more than several $10^{8}$ photons $/ \mathrm{sr} / \mathrm{s}$ is required.

Recently, a variety of femtosecond X-ray sources have been developed apart from the laser-produced plasma X-ray source. These include ultrafast hard X-rays produced by synchrotron and X-ray free electron laser (XFEL) $[15,18,19]$. However, the intensity or coherency of X-rays in synchrotrons or 
XFEL is quite high, and they are very expensive and require huge and complex facilities; moreover, it is difficult to measure many samples because of usage limitations. Laser-produced plasma X-ray sources have a comparatively small size and require only a lab-scale experimental facility. A laser-produced plasma X-ray source consists of high-power, low-repetitionrate lasers of above $100 \mathrm{~mJ}$ and $10 \mathrm{~Hz}$ [20-23]. Such a laser-plasma X-ray source requires a huge vacuum chamber for focusing such a high-power laser pulse. For time-resolved X-ray experiments, the K $\alpha$ X-ray intensity using this large-scale laser is high enough $\left(10^{9}-10^{11} \mathrm{cps} / \mathrm{sr}\right.$ with $\mathrm{Cu} \mathrm{K} \alpha$-X-ray conversion efficiency of $\left.10^{-5}-10^{-4}\right)$. However, the utilization of such ultrafast pulsed X-ray source has been limited because of the complexity of the huge vacuum system and the difficulty in managing large, high-power lasers. Problems also exist in the use of complex vacuum systems, the limitation in target forms and debris from the target caused by laser ablation. In a vacuum chamber, thin taped targets or wire targets have been used because of the space limitation in a vacuum chamber. However, the lifetime of the target is quite short (about several hours to at most a few days). It is also difficult to control the position of the taped or wire typed target within a Rayleigh length of a few micrometers. Another problem is that of debris from the target. When the target surface in a vacuum is exposed to the high-intensity laser plasma, the target materials are blown off by laser ablation and deposited onto the focusing lens, the windows of the vacuum chamber and other optics. A thin polymer cover was used to re- 
move the deposited debris. More compactly designed, more easy-to-access, short-pulsed X-ray sources are required. Recently, compact designed tabletop submillijoule to several millijoule femtosecond lasers have been applied as a short-pulsed X-ray source under a vacuum condition. The intensity from these compactly designed $\mathrm{K} \alpha \mathrm{X}$-ray sources in vacuum are $10^{8}-10^{10}$ cps/sr with K $\alpha$ X-ray conversion efficiency of $10^{-6}-10^{-5}$ [24-26]. This Xray source with this compact laser achieves the X-ray intensity required for time-resolved X-ray diffraction. It also accomplished a reduction in the size of a femtosecond laser. Nevertheless, difficulties still remain in using a huge, complex vacuum chamber system, including problems of target form, target lifetime and debris from the target. Therefore, a high-intensity X-ray source with a tabletop laser capable of operating in air would be required.

The ultrafast X-ray source for atmospheric pressure $\left(1.01 \times 10^{5} \mathrm{~Pa}\right)$ is a desirable tool for ultrafast time-resolved measurements. It is possible to reduce the size of the total X-ray source system, eliminating a huge and complex vacuum system. It is also feasible to set a long-life and large-size target in an air atmosphere regardless of the vacuum chamber. The samples measured with time-resolved X-ray diffraction can be placed close to the X-ray generating spot without a vacuum system, which enables us to utilize more efficiently the generated X-ray. Moreover, this vacuum-free X-ray system eliminates the debris problem. In atmospheric pressure, debris cannot reach the focusing lens, which is placed more than ten millimeters away from the focusing spot. With the use of helium or other gas jet, debris can be col- 
lected easily with a filter. There have been a few reports of laser-produced plasma X-ray generation at atmospheric pressure in air [27]. However, the X-ray intensity or conversion efficiency in air was quite low and explaining the relationship between the X-ray intensity and the atmosphere near the target surface was difficult. In this paper, we demonstrate a laser-plasmainduced hard X-ray radiation with tabletop femtosecond laser in various atmospheres, namely air, helium or vacuum $\left(2.7 \mathrm{~Pa}-1.3 \times 10^{4} \mathrm{~Pa}\right)$. The relationship between $\mathrm{K} \alpha \mathrm{X}$-ray conversion efficiency and the ambient atmosphere near the target surface is explained with a simple electron collision model. This model suggests that the electron mean free path in the atmosphere is the important parameter in laser-induced X-ray radiation. This result suggested the possiblity of vacuum-free high-intensity X-ray source in a helium atmospheric condition.

\section{Experimental}

Fig. 1 shows the schematic drawing of the experimental setup for ultrafast pulsed X-ray generation in various atmosphere conditions; in air, in helium atmosphere or in vacuum conditions $\left(2.7 \mathrm{~Pa}-1.3 \times 10^{4} \mathrm{~Pa}\right)$. A mode-locked Ti: sapphire laser-generated optical pulses of about 100 fs duration with wavelength $800 \mathrm{~nm}$, and the optical pulses were amplified at about 3.5 $\mathrm{mJ} /$ pulse through a regenerative amplifier (Spectra Physics Model Spitfire Pro XP) with repetition rate of $1 \mathrm{kHz}$. The laser pulse profile was TEM $\mathrm{T}_{00}$. The optical pulse had a prepulse, which was generated in the regenerative 
amplifier laser system itself as leakage though the Pockels cell before the final pulse of pulse train was switched off. The prepulse contrast to the main pulse was measured to be $8 \times 10^{-4}$, and the time separation between the prepulse and main pulse was $20 \mathrm{~ns}$. The influence of the prepulse plasma on X-ray generation can be negligible in a time regime of $10 \mathrm{~ns}$ prepulse even if the prepulse generates preplasma on the target surface [24]. The $p$-polarized optical pulses were focused into a moving copper target with infrared achromatic lens $(\mathrm{f}=40 \mathrm{~mm})$ with a spot size of $4.8 \mu \mathrm{m}$. The pulse duration of the laser pulse on the surface of the copper target was $100 \mathrm{fs}$ and the energy of optical pulse was 0.18-1.46 mJ. The moving copper target was placed in a vacuum chamber with two leak valves used for varying its vacuum level. The surface position of the copper target was controlled within $\pm 1 \mu \mathrm{m}$, which could be measured with a micrometer during motion. The ambient near the focus point in the $\mathrm{Cu}$ target system could be varied between air, helium, or vacuum $\left(2.7 \mathrm{~Pa}-1.3 \times 10^{4} \mathrm{~Pa}\right)$. For the helium ambient, the helium gas was introduced through a 1/4-inch gas nozzle and blown onto the $\mathrm{Cu}$ target surface at a flow rate of $500 \mathrm{ml} / \mathrm{min}$. For vacuum conditions, the chamber was evacuated with a dry pump with the leak valves closed $(2.7 \mathrm{~Pa})$ and with the leak valves opened $\left(1.3 \times 10^{3} \mathrm{~Pa} / 1.3 \times 10^{4} \mathrm{~Pa}\right)$.

The X-ray generated from focusing the laser pulse onto a copper target was measured with a P-intrinsic-N(PIN) Si photo detector (Amptek, XR-100CR), with a $300 \mu \mathrm{m}$ thick and $7 \mathrm{~mm}^{2}$ square silicon detector with detection efficiency of approximately $100 \%$ for an $8 \mathrm{keV}$ X-ray. The detec- 
tor was sealed with a $25 \mu \mathrm{m}$ thick Be window in which an $8 \mathrm{keV}$ X-ray penetrates without any loss. The signal from the detector was amplified with a spectroscopy amplifier (CANBERRA, 2022 Spectroscopy Amplifier) and was tallied up with a multichannel analyzer (SEIKO EG\&G, TRUMPMCA-2k). The detector was placed $1500 \mathrm{~mm}$ away from the focusing spot at an angle of 60 degrees. Under vacuum conditions, the X-ray traveled $3 \mathrm{~mm}$ in a vacuum and $1497 \mathrm{~mm}$ in air. The attenation value of $1497-1500 \mathrm{~mm}$ atmospheric air is $85 \%$ for $\mathrm{Cu} \mathrm{K} \alpha$ X-ray. In He ambient or under vacuum conditions, a $320 \mu \mathrm{m}$ thin aluminum filter was placed before the detector. This filter reduces the X-ray by $1.72 \%$ for a $\mathrm{Cu} \mathrm{K} \alpha$ X-ray. The long distance between the X-ray focusing spot, the detector and the Al filter allows us to measure the X-ray photons as a Poisson distribution for single photon counting. With a Si photo detector and a multichannel analyzer, two photons cannot be detected at once in a period on the order of $1 \mathrm{~ms}$. If more than one photon exists at the same time, the total energy of the photons is doubled with the Si photo detector. For all conditions, it took $40 \mathrm{~s}$ to obtain each X-ray spectrum.

\section{Results and Discussion}

Fig. 2 shows the typical X-ray spectra generated at the focusing spot in vacuum and in air. The X-rays generated at the focusing spot went through $1500 \mathrm{~mm}$ in air and $320 \mu \mathrm{m} \mathrm{Al}$ filter (in helium or in a vacuum) for a single photon as measured with the Si PIN photo detector and multichannel 


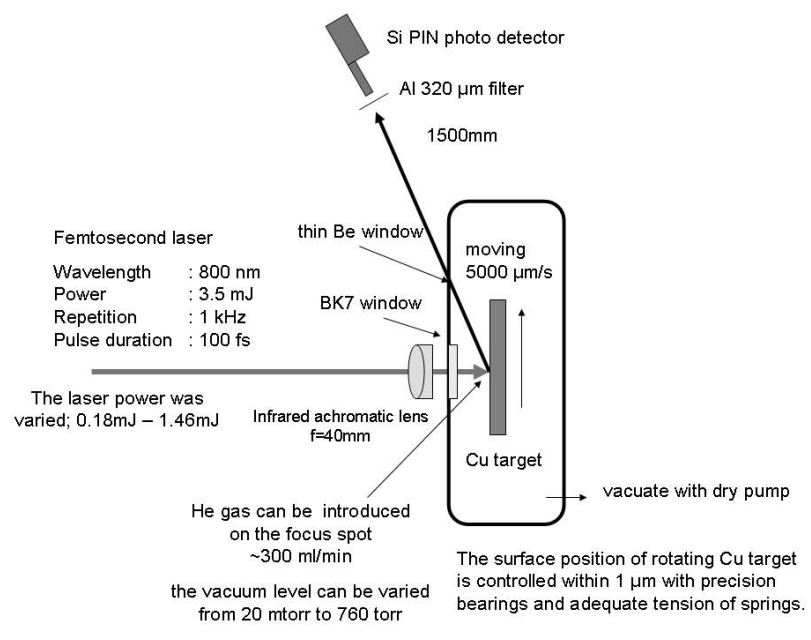

Fig. 1 Schematic drawing of the experimental setup for ultrafast pulsed X-ray generation in various ambient conditions.

analyzer. Thus, X-ray intensity was reduced depending on its energy. The energy spectra shown in Fig. 2 were calculated taking into account reduction by the air layer and the $\mathrm{Al}$ filter. The $\mathrm{X}$-ray radiation from a $p$-polarized laser is regarded as an isotropic radiation hemisphere [28]; therefore the X-ray spectra were computed into $2 \pi$. In Fig. 2 , the spectra were obtained at the plasma intensity of $3.0 \times 10^{16} \mathrm{~W} \mu \mathrm{m}^{2} / \mathrm{cm}^{2}$ at laser intensity of 1.10 $\mathrm{mJ} /$ pulse. As shown in Fig. 2, the strong $\mathrm{Cu} \mathrm{K} \alpha \mathrm{X}$-ray line (8.05 keV), $\mathrm{K} \beta$ $\mathrm{X}$-ray line $(8.91 \mathrm{keV})$ and a small part of the bremsstrahlung X-ray were found in the energy range of several keV. Fig. 2 also shows the K $\alpha$ X-ray intensity at various vacuum pressures, from $2.7 \mathrm{~Pa}$ to $1.01 \times 10^{5} \mathrm{~Pa}$ (in air); the solid line with circle symbols is the $\mathrm{K} \alpha \mathrm{X}$-ray intensity at plasma power of $3.0 \times 10^{16} \mathrm{~W} \mu \mathrm{m}^{2} / \mathrm{cm}^{2}$ plotted as a function of vacuum pressure. There was a rapid decline in $\mathrm{K} \alpha \mathrm{X}$-ray intensity as the vacuum pressure increased 


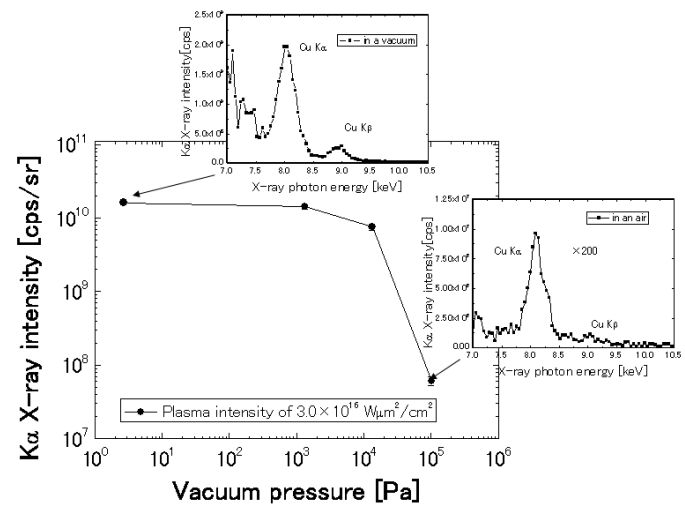

Fig. 2 The solid line with circle symbols is the $\mathrm{Cu} \mathrm{K \alpha} \mathrm{X}$-ray intensity at plasma power of $3.0 \times 10^{16} \mathrm{~W} \mu \mathrm{m}^{2} / \mathrm{cm}^{2}$ plotted as a function of vacuum level. Two X-ray spectra are shown, in a vacuum and in air.

above $1.3 \times 10^{4}$ Pa. Fig. 3 shows the spectra of high energy bremsstrahlung emission in the range of 10-14 keV in helium atmosheric condition at plasma intensity of $4.0 \times 10^{16} \mathrm{~W} \mu \mathrm{m}^{2} / \mathrm{cm}^{2}$. The hot electron temparature can be derived from Fig. 3 and the $\mathrm{K} \alpha \mathrm{X}$-ray emission is found to be produced by a distribution function of hot electrons characterized by a temperature of approximatedly $3.4 \mathrm{keV}$. This value of hot electron temperature is well corresponding to the previously reported hot electron temperture of 1-5 $\mathrm{keV} \cdot[11]$

In Fig. 4, the $\mathrm{K} \alpha \mathrm{X}$-ray conversion efficiency was plotted as a function of the plasma intensity at various ambient conditions: in a vacuum $(2.7 \mathrm{~Pa}-$ $1.3 \times 10^{4} \mathrm{~Pa}$ ) and at atmospheric pressure in helium and air. The K $\alpha$ X-ray conversion efficiency $\left(\eta_{\mathrm{K} \alpha}\right)$ is defined as $\eta_{\mathrm{K} \alpha}=n h \nu_{\mathrm{K} \alpha} / E_{\text {pulse }}$ with $n$ the 


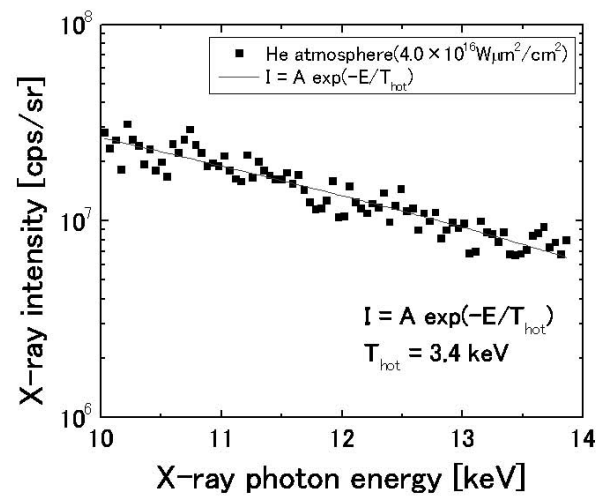

Fig. 3 X-ray intensity above X-ray photon energy of $10 \mathrm{keV}$ fitted by a Maxwellian electron distribution and the hot electron temparature was found to be $\mathrm{T}_{h o t}=3.4 \mathrm{keV}$.

number of $\mathrm{K} \alpha \mathrm{X}$-ray photons generated per pulse, $h \nu_{\mathrm{K} \alpha} \mathrm{K} \alpha \mathrm{X}$-ray energy, and $E_{\text {pulse }}$ the single pulse energy of incident laser. The plasma intensity was varied in the range $1.5 \times 10^{15}-4.0 \times 10^{16} \mathrm{~W} \mu \mathrm{m}^{2} / \mathrm{cm}^{2}$ by varying the incident laser pulse energy of $0.06-1.46 \mathrm{~mJ} /$ pulse. At this plasma energy, laser-produced plasma is absorbed into the target via a collisionless process such as resonant absorption. In any ambient condition, the conversion efficiency of the $\mathrm{K} \alpha \mathrm{X}$-ray increased as a power function up to the plasma intensity range of $1.0-2.0 \times 10^{16} \mathrm{~W} \mu \mathrm{m}^{2} / \mathrm{cm}^{2}$, because more hot electrons were generated and the energy of hot electrons is higher with higher plasma intensity. Above the plasma intensity of $2.0 \times 10^{16} \mathrm{~W} \mu \mathrm{m}^{2} / \mathrm{cm}^{2}$, the $\mathrm{Cu} \mathrm{K} \alpha$ X-ray conversion efficiency remained on a plateau. These tendencies are similar to the experimental data obtained by other groups with high-repetition 
laser in a vacuum $[25,26]$. The X-ray conversion efficiency in helium at atmospheric pressure was $5.0 \times 10^{-6}$, which was $30 \%$ of that in a vacuum of 2.7 Pa; in a vacuum of $1.3 \times 10^{4} \mathrm{~Pa}$, the conversion efficiency was $50-60 \%$ of that of a vacuum of $2.7 \mathrm{~Pa}$. Overall, in vacuum conditions $\left(2.7 \mathrm{~Pa}-1.3 \times 10^{4}\right.$ $\mathrm{Pa}$ ) and in a helium atmosphere, the conversion efficiency of the K $\alpha$ X-ray was two orders of magnitude higher than in air.

The laser power lost in air or helium plasmas was quite low, at less than $10 \%$ and less than $1 \%$, respectively. Moreover, the pulse duration of incident laser was not extended in air or helium plasmas. In a helium atmosphere, the changes in pulse profile, i.e., wavelength and pulse duration, were reported to be quite small for plasma intensity on the order of $1.0 \times$ $10^{16} \mathrm{~W} / \mathrm{cm}^{2}[29-31]$. This suggests that the effect of the reduction of the plasma intensity or breakdown in the ambient gases is negligibly-small in changes of X-ray conversion efficiency in air or helium at atmosphere. Some papers have indicated that the decrease in the X-ray conversion efficiency in ambient atmospherere was caused by the defocusing effect of laser pulse in helium or in air.[32-34] However it has also reported that the laser-plasma induced X-ray source sizes in helium flow and in vacuum were almost the same on the order of $10 \mu \mathrm{m}$.[35] The defocusing of laser pulse on the focusing spot would be occured; however it is difficult to explain the X-ray intensity reduction in ambient atmosphere only with defocusing effect quantitatively. The interactions between the generated electrons and the ambient atmo- 


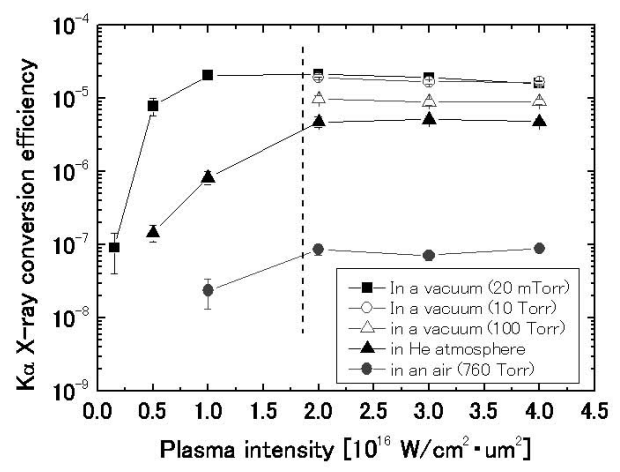

Fig. 4 The K $\alpha$ X-ray conversion efficiency, plotted as a function of the plasma intensity under various conditions. Symbols are indicated in the inset legend. The vertical dashed line shows the boundary of the intensity increasing area and the area of the plateau.

spheric atoms/molecules should be also considered to describe the proper model for the laser-plasma induced X-ray generation.

At the plasma intensities of $2.0 \times 10^{16}, 3.0 \times 10^{16}$ and $4.0 \times 10^{16}$ $\mathrm{W} \mu \mathrm{m}^{2} / \mathrm{cm}^{2}$, the $\mathrm{K} \alpha$ X-ray conversion efficiency in air or a vacuum of $1.3 \times 10^{3} \mathrm{~Pa}$ or $1.3 \times 10^{4} \mathrm{~Pa}$ was normalized with that in a vacuum of 2.7 Pa. In Fig. 4, the K $\alpha$ X-ray conversion efficiency normalized with that in a vacuum of 2.7 $\mathrm{Pa}$ was plotted as a function of pressure and electron mean free path in that atmosphere for plasma intensities of 2.0-4.0 $\times 10^{16}$ $\mathrm{W} \mu \mathrm{m}^{2} / \mathrm{cm}^{2}$. Regarding the electron generation and acceleration process, the target surface on the focusing spot changes into a near-solid-density plasma by the incident laser pulse. The expansion region of the electrons in 
plasma is on the order of the incident pulse wavelength from the surface, within the time scale of several fs. After traveling through the expansion region, the electrons are accelerated by the incident laser pulse into the target. When there are atoms/molecules of ambient gas near the focusing spot, the electron can interact with these atoms/molecules before and while being accelerated. The electron traveling distance without interaction with the ambient gases is the electron mean free path in this atmosphere. The interaction cross-section between the electron and atoms/molecules is given by the simple electron collision model. The electron mean free path is expressed as the equation

$$
\lambda=k T /\left(\pi r^{2} p\right)
$$

where $\lambda$ is the electron mean free path in the ambient, $k$ is the Bolzmann constant, $r$ is the radius of the molecule and $T$ and $p$ are temperature (20 degrees C) and pressure of the ambient gas. In air the pressure is $1.01 \times 10^{5}$ $\mathrm{Pa}$ and $\lambda$ is $0.34 \mu \mathrm{m}$. In vacuums of $1.3 \times 10^{4} \mathrm{~Pa}, 1.3 \times 10^{3} \mathrm{~Pa}$ and $2.7 \mathrm{~Pa}$, the values of $\lambda$ are $2.6 \mu \mathrm{m}, 26 \mu \mathrm{m}$ and $13 \mathrm{~mm}$, respectively (Fig. 4, lower horizontal axis). In the simple electron collision model, electrons collide with the atoms/molecules in the atmosphere gas before or during their acceleration by the incident pulse. The electrons that collided with the ambient gas cannot reach the surface of the target material and therefore do not participate in the generation of $\mathrm{K} \alpha \mathrm{X}$-rays of the target materials. The energy of hot electrons in the plasma is in the range of $1-5 \mathrm{keV}$, and ions of the target materials in the plasma also have almost the same energy. In the first several 
fs, the ions in the plasma do not have enough velocity and remain near the target surface. The number of electrons accelerated by the incident pulse decreases exponentially as the electrons move into the ambient atmosphere due to the interaction between electrons and atoms/molecules in ambient atmosphere. The number of X-ray photons is proportional to the number of accelerated electrons that arrived near the target material surface. Thus, the X-ray intensity can be expressed by the equation

$$
I=I_{0} \exp (-A / \lambda)
$$

Here, $I_{0}$ is the intensity of the generated X-ray on the target, $I$ is the intensity of the measured X-ray in the atmosphere and $A$ and $\lambda$ are average traveling length and electron mean free path in the atmosphere. In Fig. 4, the solid line represents the modified form of eq. (2), i.e.,

$$
I / I_{0}=\exp (-A / \lambda)
$$

with $A=1.47 \mu \mathrm{m}$.

The normalized X-ray conversion efficiency was well-fitted with the equation of the simple electron collision model. At plasma energies of $2.0 \times 10^{16}$, $3.0 \times 10^{16}$ and $4.0 \times 10^{16} \mathrm{~W} \mu \mathrm{m}^{2} / \mathrm{cm}^{2}$, the values of $A$ were fitted as $1.76 \pm$ $0.13,1.67 \pm 0.21$ and $1.31 \pm 0.13 \mu \mathrm{m}$. This means that the electrons in the plasma traveled 1-2 $\mu \mathrm{m}$ in the atmosphere before an incidence occurred with the target surface or the near-solid-density plasma of the target materials. Fig. 4 also shows the relationship between the normalized X-ray conversion efficiency and the electron mean free path reported by Serbanescu et. al. 


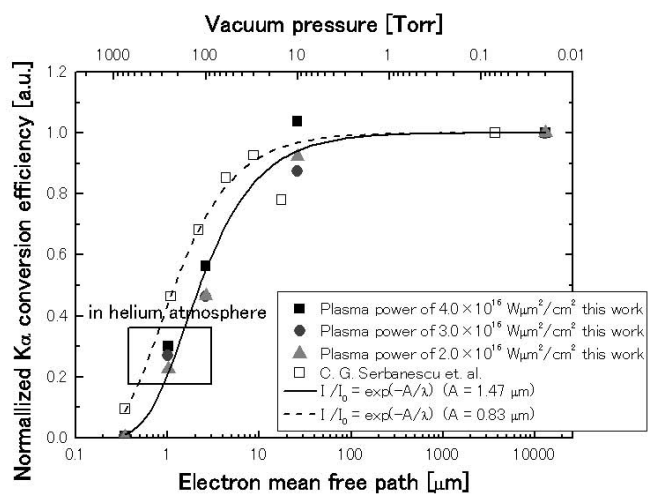

Fig. 5 Comparison between the normalized $\mathrm{K} \alpha \mathrm{X}$-ray conversion efficiency in this work and in Serbanescu et al. [36]. Symbols are indicated in the inset legend.

[36] at a plasma intensity of $6.9 \times 10^{16} \mathrm{~W} / \mathrm{cm}^{2}$, which also fitted well with the equations of the simple electrons collision model. The value of $A$ in the atmosphere was $0.83 \pm 0.11 \mu \mathrm{m}$ (Fig. 4, dotted line). Regarding the helium ambient, $\lambda$ was calculated to be $1.01 \mu \mathrm{m}$ at 760 torr in air. The normalized X-ray conversion efficiency in helium ambient also fitted successfully with the equations of the simple electron collision model (Fig. 4). This means that the X-ray conversion efficiency could be described by eq. (2) regardless of the specific atoms/molecules in the atmosphere. The electron mean free path at atmospheric pressure is also suggested as a universal parameter in generating ultrafast pulsed X-ray in any ambient at atmospheric pressure.

The electron traveling the length of the atmosphere should vary with the focusing conditions and the plasma intensity on the focusing spot. Generally, the gradient of the electrical field increases with higher plasma in- 
tensity, and the focusing spot size and the Rayleigh length of the incident pulse on the spot vary with focusing optics. Above a plasma intensity of 2.0 $\times 10^{16} \mathrm{~W} \mu \mathrm{m}^{2} / \mathrm{cm}^{2}$, the average of electron traveling length in the atmosphere was 1-2 $\mu \mathrm{m}$ and the electron mean free path of helium at atmospheric pressure was $1.01 \mu \mathrm{m}$. Therefore, the X-ray intensity in helium ambient at atmospheric pressure was calculated to be $20-40 \%$ of its value in vacuum conditions. We also obtained an X-ray conversion efficiency of $5.0 \times 10^{-6}$, which was $30 \%$ of that at $2.7 \mathrm{~Pa}$, suggesting that the high-intensity ultrafast pulsed K $\alpha$ X-ray source in helium at $1.01 \times 10^{5} \mathrm{~Pa}$ can be realized without vacuum.

\section{Conclusion}

Hard X-ray radiation with millijoule and high-repetition-rate Ti: sapphire laser was demonstrated in various ambient and pressure conditions in air, helium or various vacuum conditions $\left(2.7 \mathrm{~Pa}-1.3 \times 10^{4} \mathrm{~Pa}\right) . \mathrm{Cu} \mathrm{K} \alpha$ X-ray radiation was obtained by focusing the $0.06-1.46 \mathrm{~mJ} / \mathrm{pulse}, 100 \mathrm{fs}$ and $1 \mathrm{kHz}$ repetition femtosecond laser on a solid $\mathrm{Cu}$ target with a plasma intensity of $1.5 \times 10^{15}-4.0 \times 10^{16} \mathrm{~W} \mu \mathrm{m}^{2} / \mathrm{cm}^{2}$. The normalized K $\alpha$ X-ray conversion efficiency in various conditions indicated that the relationship between the K $\alpha$ X-ray conversion efficiency and the atmosphere near the target surface can be explained with the simple electron collision model. In this model, it is suggested that the electron mean free path in the atmospheric condition is an important parameter in the generation of the ultrafast pulsed X-ray 
in any atmospheric condition. The electron traveling length in ambient atmosphere were well fitted to 1-2 $\mu \mathrm{m}$ and electron mean free path in helium atmosheric pressure was $1.01 \mu \mathrm{m}$. Therefore, with eq. (2), it is also suggested that the $20-40 \%$ intensity ultrafast pulsed $\mathrm{K} \alpha \mathrm{X}$-ray, compared with the vacuum condition, is generated even in a helium ambient at $1.01 \times 10^{5}$ $\mathrm{Pa}$, and a high-intensity ultrafast pulsed X-ray source was realized without a vacuum system. This $\mathrm{X}$-ray source enables us to avoid difficulties and complexities such as the target form or debris problem and also gives us stable and long lifetime ultrafast pulsed X-ray.

Acknowledgements This work is supported by Core Research for Evolutional Science and Technology (CREST) of the Japan Science and Technology Agency (JST). We would like to thank Dr. Aoki, Dr. Seki, Dr. Ninomiya, Dr. Nakata, Mr. Ichiki and Mr. Yamada from Kyoto University for discussions regarding X-ray generation systems.

\section{References}

1. R.M. More, Z. Zinamon, K.H. Warren, R. Falcone, M. Murnane, J. Physique C7 49, 43 (1988).

2. E.G. Gamaly, Laser Particles and Beams 12, 185 (1994).

3. P. Gibbon and E. Forster, Plasma Phys. Controlled Fusion 38, 769 (1996).

4. R. Fedosejevs, R. Ottmann, R. Sigel, G. K?hnle, S. Szatmari, and F. P. Schafer, Phys. Rev. Lett. 64, 1250 (1990).

5. D. F. Price, R. M. More, R. S. Walling, G. Guethlein, R. L. Shepherd, R.E. Stewart, and W. E. White, Phys. Rev. Lett. 75, 252 (1995). 
6. D. W. Forslund, J. M. Kindel, and K. Lee, Phys. Rev. Lett. 39, 284 (1977).

7. K. Eidmann, J. Meyer-ter-Vehn, T. Schlegel, and S. Huller, Phys. Rev. E62, $1202(2000)$.

8. E.S. Weibel, Phys. Fluids 10, 741 (1967).

9. S.C. Wilks, Phys. Fluids B 5, 2603 (1993).

10. S.C. Wilks, W.L. Kruer, M. Tabak, A.B. Langdon, Phys. Rev. Lett. 69, 1383 (1992)

11. W. Rozmus, V.T. Tikhonchuk, R. Cauble, Phys. Plasmas 3, 360 (1996).

12. K.G. Nakamura, S. Ishii, S. Ishitsu, M. Shiokawa, H. Takahashi, K. Dharmalingam, J. Irisawa, Y. Hironaka, K. Ishioka, M. Kitajima, Appl. Phys. Lett. 93, 061905 (2008).

13. C. Rose-Petruck, R. Jimenez, T. Guo, A. Cavalleri, C. W. Siders, F. Raksi, J. A. Squier, B. C.Walker, K. R. Wilson , C. P. J. Barty, Nature (London) 398, 310 (1999).

14. K. Sokolowski-Tinten, C. Blome, J. Blums, A. Cavalleri, C. Dietrich, A. Tarasevitch, I. Uschmann, E. Forster, M. Kammler, M. Horn-von-Hoegen, D. von der Linde, Nature (London) 422, 287 (2003).

15. A. M. Lindenberg, J. Larsson, K. Sokolowski-Tinten, K. J. Gaffney, C. Blome, O. Synnergren, J. Sheppard, C. Caleman, A. G. MacPhee, D. Weinstein, D. P. Lowney, T. K. Allison, T. Matthews, R. W. Falcone, A. L. Cavalieri, D. M. Fritz, S. H. Lee, P. H. Bucksbaum, D. A. Reis, J. Rudati, P. H. Fuoss, C. C. Kao, D. P. Siddons, R. Pahl, J. Als-Nielsen, S. Duesterer, R. Ischebeck, H. Schlarb, H. Schulte-Schrepping, Th. Tschentscher, J. Schneider, D. von der Linde, O. Hignette, F. Sette, H. N. Chapman, R. W. Lee, T. N. Hansen, S. Techert, J. S. Wark, M. Bergh, G. Huldt, D. van der Spoel, N. Timneanu, J. Hajdu,R. A. 
Akre, E. Bong, P. Krejcik, J. Arthur, S. Brennan, K. Luening, J. B. Hastings, Science 308, 392 (2005).

16. D. M. Fritz, D. A. Reis, B. Adams, R. A. Akre, J. Arthur, C. Blome, P. H. Bucksbaum,A. L. Cavalieri, S. Engemann, S. Fahy, R. W. Falcone, P. H. Fuoss, K. J. Gaffney, M. J. George, J. Hajdu, M. P. Hertlein, P. B. Hillyard, M. Hornvon Hoegen, M. Kammler, J. Kaspar, R. Kienberger, P. Krejcik, S. H. Lee, A. M. Lindenberg, B. McFarland, D. Meyer, T. Montagne, ?. D. Murray, A. J. Nelson, M. Nicoul, R. Pahl, J. Rudati, H. Schlarb, D. P. Siddons, K. Sokolowski-Tinten, Th. Tschentscher, D. von der Linde, J. B. Hastings, Science 315, 633 (2007).

17. K. Scokilowski-Tinten, D. von der Linde, J. Phys. Condens. Matter 16 R1517 (2004)

18. P. Lucas, S. Webber, Eds. (IEEE, Piscataway, NJ, 2003), p. 423

19. R. Service, Science 298, 1356 (2002).

20. M. Yoshida, Y. Fujimoto, Y. Hironaka, K.G. Nakamura, K. Kondo,M. Ohtani,

H. Tsunemi: Appl. Phys. Lett. 73, 2393 (1998).

21. E.C. Eder, G. Pretzler, E. Fill, K. Eidmann, A. Saemann: Appl. Phys. B70, $211(2000)$

22. E. Fill, J. Bayerl, R. Tommasini: Rev. Sci. Instrum. 73, 2190 (2002).

23. C.W. Siders, A. Cavalleri, K. Sokolowski-Tinten, T. Guo, C. T?th, R. Jimenez,

C. Rose-Petruck, M. Kammler,M. Horn von Hoegen, D. von der Linde, K.R. Wilson, C.P.J. Barty: SPIE Proc. 3776, 302 (1999).

24. C.L. Rettig, W.M. Roquemore, J.R. Gord, Appl. Phys. B93, 365 (2008).

25. M. Hagedorn, J. Kutzner, G. Tsilimis, H. Zacharias, Appl. Phys. B77, 49 (2003)

26. C. G. Serbanescu, J. A. Chakera, and R. Fedosejevs, Rev. Sci. Instrum. 78, $103502(2007)$. 
27. N. Takeyasu, Y. Hirakawa, T. Imasaka, Rev. Sci. Instrum. 72, 3940 (2001).

28. Y. Hironaka, K.G. Nakamura, K. Kondo, Appl. Phys. Lett. 77, 4110 (2000).

29. W.M. Wood, C.W. Siders, M.C. Downer, Phys Rev. Lett. 67, 3523 (1991).

30. B.M. Penetrante, J.N. Bardsley, W.M. Wood, C.W. Siders, M.C. Downer, J.

Opt. Soc. Am. B 9, 2032 (1992).

31. F.V. Hartemann, A.L. Troha, H.A. Baldis, A.Gupta, A.K. Kerman, E.C. Landahl, N.C. Luhmann Jr., J.R. van Meter, Astrophys. J. Supplement Series 127, $347(2000)$.

32. T. Auguste, P. Monot, L.A. Lompre, G. Mainfray, C. Manus, Opt. comm. 89, $145(1992)$.

33. Y.M. Li, J.N. Broughton, R. Fedosejevs, T. Tomie, Opt. comm. 93, 366 (1992).

34. D. Umstadter, J. Phys. D: Appl. Phys. 36, R151 (2003).

35. B. Hou, J. Easter, K. Krushelnick, J.A. Nees, Appl. Phys. Lett. 92, 161501 (2008).

36. C.G. Serbanescu, J. Santiago, R. Fedosejevs, Proc. of SPIE 5196, 344 (2004). 